mống mắt do vậy, nguyên nhân gây VMBĐ lại được cộng hợp, tuy nhiên có khoảng thời gian giữa 2 lần phẩu thuật và laser tạo hình nên phần nào hạn chế được các mức đô của viêm, hạn chế ảnh hưởng tới kết quả phẫu thuật cuối cùng.

Ngoài ra, khi đánh giá ảnh hưởng của tai biến, biến chứng lên kết quả phẫu thuật, chúng tôi không thây sự khác biệt giữa nhóm có biến chứng và nhóm không có biến chứng, điều này cho thấy hiệu quả của việc phát hiện và xử lý biến chứng sớm có ý nghî̉a hết sức quan trọng đến kết quả phẫu thuật cuối cùng

\section{KẾT LUẬN}

Phẫu thuật mống mắt chu biên phối hợp laser tạo hình mống mắt chu biên khá an toàn, mặc dù có một tỷ lệ tai biến, biến chứng nhất định nhưng ở mức độ nhẹ, có thể can thiệp dễ dàng không ảnh hưởng đến kết quả cuối cùng.

TÀI LIỆ THAM KHẢO
1. Quigley HA, Broman AT. The number of people with glaucoma worldwide in 2010 and 2020. Br J Ophthalmol; 90:262-7. 2006

2. Nongpiur ME, Ku JY, Aung T. Angle closure glaucoma: a mechanistic review. Curr Opin Ophthalmol; 22:96-101. 2011

3. Edmunds, B., et al. The national survey of trabeculectomy. III. Early and late complications. Eye 16.3: 297-303.2002

4. Playfair, T. JUSTIN, and PETER G. Watson. Management of acute primary angle-closure glaucoma: a long-term follow-up of the results of peripheral iridectomy used as an initial procedure. British Journal of Ophthalmology 63.1,17-22. 1979

5. Ritch R, Tham CC, Lam DS. Argon laser peripheral iridoplasty (ALPI): an update. Surv Ophthalmol. 2007; 52:279-88.

6. Ritch R, Tham CC, Lam DS. Long-term success of argon laser peripheral iridoplasty in the management of plateau iris syndrome. Ophthalmology; 111:104-8.2004

7. Lingam Vijaya, Panday Manish, George Ronnie, and B Shantha. Management of complications in glaucoma surgery. Indian J Ophthalmol, S131-S140.2011

\title{
NGHIÊN CỨU TÌNH TRANG DINH DƯỠNG Ở BÊNH NHÂN BÊ̂NH THÂN MẠN GIAI ĐOẠN CUỐI LỌC MÁU CHU KỲ TẠI BỆNH VIỆN HỮU NGHỊ ĐA KHOA NGHỆ AN
}

\section{TÓM TẮT}

Muc tiêu: Khảo sát tình trạng dinh dưỡng và các yếu tố liên quan ở bệnh nhân bệnh thận mạn giai đoạn cuối lọc máu chu kỳ. Phưởng pháp nghiên cứu: Nghiên cứu mô tả cắt ngang được thực hiên trên 104 bệnh nhân bệnh thận mạn giai đoạn cuối lọc máu chu kỳ tai khoa Nôi thẩn - Thân nhân tao bênh viên hữu nghị đa khoa Nghệ An. Kết quả: (1)Tỷ lệ bệnh nhân thiếu cân theo BMI là $26,1 \%$; tỷ lê bênh nhân có albumin huyết thanh thấp là $26,9 \%$; đánh giá nguy cơ tổng thể theo chỉ số SGA thì tỷ lệ nguy cơ thiểu dưỡng mức độ $B$ là 40,4\%. (2) 14,4\% bệnh nhân thiếu máu năng; $31,7 \%$ bênh nhân thiếu máu vừa và $47,2 \%$ bệnh nhân thiếu máu nhẹ. (3) Có mối liên quan giữa tình trang suy dinh dưỡng với thời gian loc máu $(p<0,05)$. Kết luận: Tỷ lệ thiếu dưỡng ở bệnh nhân bênh thân man giai đoạn cuối loc máu chu kỳ̀ còn cao, đặc biệt ở nhóm bệnh nhân có thời gian lọc máu lọc máu trên 5 năm. Tư khóa: Suy dinh dưỡng, Bệnh thận mạn giai đoạn cuối

*Đại học Y khoa Vinh

Chịu trách nhiệm chính: Nguyễn Văn Tuấn

Email: tuanminh1975@gmail.com

Ngày nhận bài: 6.5.2021

Ngày phản biên khoa học: 25.6.2021

Ngày duyệt bài: 6.7.2021
Nguyễn Văn Tuấn*

SUMMARY

NUTRITIONAL STATUS IN PATIENTS WITH END-STAGE RENAL DISEASE ON DIALYSIS IN NGHE AN FRIENDSHIP GENERAL HOSPITAL

Objectives: To examine nutritional status and related factors in patients with ESRD on dialysis. Research methodology: A Cross-sectional descriptive study were conducted in 104 the patients with ESRD on dialysis at the Department of Internal Nephrology - Hemodialysis at the Nghe An Friendship General Hospital. Results: (1) The proportion of underweight patients according to BMI is $26,1 \%$; the proportion of patients with low serum albumin is 26,9\%; assessing the overall risk according to the SGA index, the risk of level B of malnutrition is $40,4 \%$. (2) $14,4 \%$ of patients had severe anemia; $31,7 \%$ of patients had moderate anemia and $47,2 \%$ of patients had mild anemia. (3) There is a relationship between malnutrition and dialysis time $(p<0,05)$. Conclusion: The rate of malnutrition in patients with ESRD on dialysis is still high, especially in patients with dialysis time more than 5 years.

Key words: Malnutrition, ESRD

\section{I. ĐẶT VẤN ĐỀ}

Bệnh thận mạn đang trở thành bệnh lý phổ biến hiện nay với tỷ lệ mắc bệnh ngày càng gia 
tăng do nhiều nguyên nhân khác nhau, điều trị khó khăn, tốn kém và là hệ quả tất yếu của việc không ngừng gia tăng bệnh đái tháo đường và tăng huyết áp.

Hiện nay, ở Việt Nam chưa có số liệu thống kê chính xác toàn quốc. Ước tính 6 triệu dân bị bệnh thận mạn, chiếm 6,73\% dân số. Khoảng 80.000 bệnh nhân suy thận mạn giai đoạn cuối và chỉ $10 \%$ bênh nhân được điều trị loc máu.

Mặc dù có những cải tiến đáng kể trong kỹ thuật điêu trị thay thế thận nhưng tỷ lệ mắc bệnh và tử vong ở những bệnh nhân bệnh thận mạn giai đoan cuối vẫn còn duy trì ở mức cao. Trong số các yếu tố ảnh hưởng bất lợi trên kết cục lâm sàng của nhóm bệnh nhân này thì tình trạng suy dinh dưỡng protein - năng lượng đóng vai trò quan trọng [8].

Vì thế chúng tôi tiến hành nghiên cứu đề tài này nhằm mục tiêu: "Khảo sát tình trạng dinh dưỡng và các yêu tố liên quan ở bệnh nhân bệnh thận mạn giai đoạn cuối lọc máu chu kỳ".

\section{II. ĐỐI TƯỢNG VÀ PHƯƠNG PHÁP NGHIÊN CứU}

1. Địa điểm nghiên cứu: Khoa Nội thậnthận nhẩn tạo, Bệnh viện hữu nghị đa khoa tỉnh Nghẹ An

2. Đối tượng nghiên cứu:

- Tiêu chuấn lứa chọn: Bệnh nhân được chẩn đoán bệnh thận mạn giai đoạn cuối lọc máu chu kỳ và đồng ý tham gia nghiên cứu tại khoa Nội Thận - Thận nhân tạo, Bệnh viện hữu nghị đa khoa tỉnh Nghệ An.

- Tiêu chuẩn loaí trừ:

+ Bệnh nhân đang dùng các thuốc amiodarone, oestrogen và các loại thuốc ngừa thai đường uống, corticosteroid, androgens, kháng viêm non-steroid liều cao, cường tuyến thượng thận, bệnh Hodgkin, bệnh cường giáp, bệnh gan nặng.

+ Bệnh nhân và gia đình không đồng ý tham gia nghiên cứu.

\section{Phương pháp nghiên cứu}

3.1. Cỡ mâuu: 104 bệnh nhân bệnh thận mạn giai đoạn cuối lọc máu chu kỳ tại khoa Nội Thận - Thận nhân tạo, Bệnh viện hữu nghị đa khoa Nghệ An thỏa mãn tiêu chuẩn lựa chọn và tiêu chuẩn loại trừ được đưa vào nghiên cứu.

3.2. Phương pháp chọn mẫu: Chọn mẫu thuận tiện.

3.3. Thiết kế nghiên cứu: Nghiên cứu mô tả cắt ngang có phân tích.

3.4. Các tiêu chuẩn, phân loại, đánh giá sử dụng trong nghiên cứu

3.4.1. Chẩn đoán và phân loại thiếu máu: Theo WHO: thiếu máu khi $\mathrm{Hb}<130 \mathrm{~g} / \mathrm{l}$ ở nam và $\mathrm{Hb}<120 \mathrm{~g} / \mathrm{l}$ ở nữ [1].

3.4.2. Đánh giá dinh dưỡng:

*Công thức tính chỉ số khối cơ thể (BMI): Cân nặng $(\mathrm{kg})$

$$
\operatorname{BMI}\left(\mathrm{kg} / \mathrm{m}^{2}\right)=
$$

Nhân định kết quả:

$$
\text { (Chiêu cao })^{2}\left(\mathrm{~m}^{2}\right)
$$

Thấp cẩn: $\mathrm{BMI}<18,5$

Thừa cân: BMI từ $23-24,9$

Bình thường: BMI từ 18,5-22,9

Béo phì độ I: BMI từ $25-29,9$

Béo phì độ II: $\mathrm{BMI} \geq 30$.

*Phân loại dinh dưỡng theo albumin:

\begin{tabular}{|c|c|}
\hline Tình trạng dinh dưỡng & Albumin (g/l) \\
\hline - Bình thường & $\geq 35$ \\
\hline - SDD nhẹ & $28-<35$ \\
\hline - SDD trung bình & $21-\leq 28$ \\
\hline - SDD nặng & $\leq 21$ \\
\hline
\end{tabular}

\begin{tabular}{|c|c|}
\hline Mức độ SDD & Chỉ số SGA \\
\hline - Mức A 9-12 điểm & Không có nguy cơ SDD \\
\hline - Mức B 4-8 điểm & Nguy cơ SDD mức độ nhe \\
\hline $0-3$ điểm & \\
\hline
\end{tabular}

*Phân loại nguy cơ SDD theo chỉ số SGA [7]:

4. Xử lý số liệu: - Số liệu được xử lý bằng phần mềm SPSS 20.0 .

- Sử dụng ANOVA test để so sánh trung bình các quan sát nếu biến có phân bố chuẩn.

- Sử dụng test X2 để so sánh sự khác biệt về tỷ lệ phần trăm.

\section{KẾT QUẢ NGHIÊN CứU}

\begin{tabular}{|c|c|c|c|c|c|c|c|}
\hline \multirow{2}{*}{ Chỉ số BMI } & \multicolumn{2}{|c|}{ Nam } & \multicolumn{2}{|c|}{$\mathbf{N} \tilde{u}$} & \multicolumn{2}{|c|}{ Chung } & \multirow{2}{*}{$\mathbf{p}$} \\
\hline & $\mathbf{n}$ & $\%$ & $\mathbf{n}$ & $\%$ & $\mathbf{n}$ & $\%$ & \\
\hline Nhẹ cân & 19 & 35,2 & 8 & 16 & 27 & 26,1 & 0,090 \\
\hline Bình thường & 32 & 59,3 & 41 & 82 & 73 & 70,1 & 0,058 \\
\hline Thừa cân, béo phì & 3 & 5,5 & 1 & 2 & 4 & 3,8 & 0,251 \\
\hline Trung bình BMI & \multicolumn{2}{|c|}{$20,19 \pm 2,52$} & \multicolumn{2}{|c|}{$19,91 \pm 1,98$} & \multicolumn{2}{|c|}{$20,06 \pm 2,27$} & 0,481 \\
\hline Tổng số & 54 & 100 & 50 & 100 & 104 & 100 & \\
\hline
\end{tabular}

Bảng 1. Tỷ lệ suy dinh dưỡng theo chỉ số BMI của đôî tượng nghiên cứu

Nhận xét: Tỷ lệ bệnh nhân thiểu dưỡng theo chỉ số BMI là 26,1\%. 
Bảng 2. Tỷ lệ suy dinh dướng theo nồng độ albumin huyêt thanh của đôî tượng nghiên cứu

\begin{tabular}{|c|c|c|c|c|c|c|}
\hline \multirow{2}{*}{$\begin{array}{c}\text { Albumin } \\
\text { huyêtt thanh (g/I) }\end{array}$} & \multicolumn{2}{|c|}{ Nam } & \multicolumn{3}{c|}{ Nữ } & \multicolumn{2}{c|}{ Chung } \\
\cline { 2 - 7 } & $\mathrm{n}$ & $\%$ & $\mathrm{n}$ & $\%$ & $\mathrm{n}$ & $\%$ \\
\hline$<35$ & 16 & 29,6 & 12 & 24,0 & 28 & 26,9 \\
\hline$\geq 35$ & 38 & 70,4 & 38 & 76,0 & 76 & 73,1 \\
\hline Tống số & $\mathbf{5 4}$ & $\mathbf{1 0 0}$ & $\mathbf{5 0}$ & $\mathbf{1 0 0}$ & $\mathbf{1 0 4}$ & $\mathbf{1 0 0}$ \\
\hline p & \multicolumn{5}{|c|}{0,336} \\
\hline
\end{tabular}

Nhân xét: Tỷ lê bênh nhân thiếu dưỡng theo nồng độ albumin huyết thanh là 26,9\%.

Bảng 3. Chỉ số sằt huyết thanh của đối tượng nghiên cứu

\begin{tabular}{|c|c|c|c|c|c|c|c|}
\hline \multirow{2}{*}{$\begin{array}{c}\text { Fe huyết } \\
\text { thanh }(\mu \mathrm{mol} / \mathrm{I})\end{array}$} & \multicolumn{2}{|c|}{ Nam } & \multirow{2}{*}{$\begin{array}{l}\text { Fe huyêt thanh } \\
(\mu \mathrm{mol} / \mathrm{I})\end{array}$} & \multicolumn{2}{|c|}{ Nũ̃ } & \multicolumn{2}{|c|}{ Tống số } \\
\hline & $\mathbf{n}$ & $\%$ & & $\mathbf{n}$ & $\%$ & $\mathbf{n}$ & $\%$ \\
\hline$<11$ & 34 & 63 & $<7$ & 18 & 36 & 52 & 50 \\
\hline $11-27$ & 20 & 37 & $7-26$ & 30 & 60 & 50 & 48,1 \\
\hline$>27$ & 0 & 0 & $>26$ & 2 & 4 & 2 & 1,9 \\
\hline Tống số & 54 & 51,9 & Tống số & 50 & 48,1 & 104 & 100 \\
\hline
\end{tabular}

Nhận xét: Nồng độ sắt huyết thanh trong ngưỡng bình thường chiếm $48,1 \%$, tỉ lệ của nữ là $60 \%$, nhiều hơn so với nam giới $37 \%$.

Bảng 5. Mối liên quan giữa tỷ lệ SDD theo các hình thức đánh giá với thời gian lọc máu của đối tượng nghiên cứu

\begin{tabular}{|c|c|c|c|c|c|}
\hline \multicolumn{2}{|c|}{ Tình trạng SDD } & $<\mathbf{1}$ năm (n, \%) & $\mathbf{1}$ - 5 năm (n, \%) & > 5 năm (n, \%) & p \\
\hline BMI & SDD & $0(0)$ & $3(2,9)$ & $24(23,1)$ & 0,038 \\
\hline Albumin & SDD & $0(0)$ & $6(5,8)$ & $22(21,2)$ & 0,046 \\
\hline SGA & SDD & $0(0)$ & $18(1,9)$ & $3(38,6)$ & 0,033 \\
\hline
\end{tabular}

Nhận xét: Có mối liên quan giữa tỷ lệ SDD qua cách đánh giá BMI, albumin và SGA với thời gian lọc máu $(p<0,05)$.

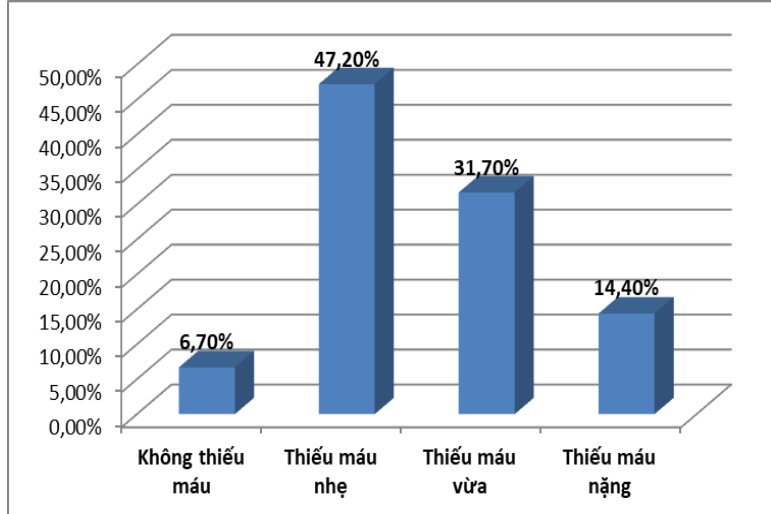

Biểu đồ 1. Tỷ lệ thiếu máu theo các mức độ của đối tượng nghiêu cứu

Nhân xét: $93,3 \%$ số bệnh nhân có thiếu máu, trong đó $14,4 \%$ số bệnh nhân thiếu máu mức đôn nặng.

Bảing 4. Tỷ lệ suy dinh dưỡng theo phương pháp SGA của đôî tướng nghiên cứu

Phân loại thiếu dưỡng

theo chỉ số SGA

\begin{tabular}{l|c|c}
\hline - Bình thường $(9-12)$ & 62 & 59,6 \\
\hline
\end{tabular}

\begin{tabular}{|l|l|l}
\hline - Suy dinh dương nhẹ $(4-8)$ & 42 & 40,4 \\
\hline
\end{tabular}

\begin{tabular}{|c|c|c|}
\hline - Suy dinh dưỡng nặng $(0-3)$ & 0 & 0 \\
\hline Tống số & $\mathbf{1 0 4}$ & $\mathbf{1 0 0}$ \\
\hline
\end{tabular}

Nhận xét: Suy dinh dưỡng mức độ nhẹ có
42 bệnh nhân chiếm 40,4\%; 62 bệnh nhân chiếm $59,6 \%$ không có suy dinh dưỡng. Không có bệnh nhân nào có nguy cơ suy dinh dưỡng mức độ nặng.

\section{BÀN LUÂN}

Tình trạng dinh dưỡng của đối tượng nghiên cứu. Nghiên cứu này chỉ ra rằng số bệnh nhân có chỉ số $B M I<18,5$ chiếm $26,1 \%$, tỷ lệ của Nguyễn Thị Vân Anh năm 2008 là 41,0\% và tương tự như nghiên cứu của Nguyễn Thị Thu Hà năm 2005 là 38,7\%. Nghiên cứu của Hisham Mostafa Tawfik (2019) trên bệnh nhân bệnh thận mạn lọc máu cho thấy tỷ lệ suy dinh dưỡng ở bệnh nhân loc máu theo BMI là 40,0\% [4]. Nhiều nghiên cứu trên thế giới đưa ra kết luận chỉ số BMI liên quan một cách có ý nghĩa với nguy cơ tử vong. BMI thấp điều đó chứng tỏ là giảm cả khối cơ và khối mõ cơ thể. Tỷ lệ bệnh nhân thừa cân béo phì trong nghiên cứu này chiếm $3,8 \%$, tuy thấp nhưng phần nào cũng chứng tỏ vấn đề về sức khỏe của một bộ phận xã hội hiện nay ở nước ta chủ yếu tập trung ở các thành phố lớn điều kiện kinh tế khá giả, ăn uống đầy đủ và dư thừa các chất dinh dưỡng gây nguy cơ cao mắc những bệnh rối loạn mỡ máu, tăng huyết áp, đái tháo đường...

Phương pháp SGA là phương pháp đánh giá tổng thể đổi tượng, một phương pháp có nhiêu ưu điểm và được nhiều nghiên cứu trên thế giới áp dụng hiện nay. Theo phương pháp này, trong 
nghiên cứu của chúng tôi tỷ lệ không có nguy cơ suy dinh dưỡng là $59,6 \%$, nguy cơ suy dinh dưỡng mức độ nhe là 40,4\%. Mức độ suy dinh dưỡng nhe của Nguyễn Thị Vân Anh năm 2008 là $77 \%$. Nghiên cứu của Jin Woo Wi và cộng sự (2017) trên bệnh nhân lọc máu ở Hàn Quốc cho thây tỷ lệ SGA 5 điểm là $7,0 \%$, SGA 6 điểm là $52,1 \%$ và tỷ lệ bệnh nhân có SGA 7 điểm là 40,8\% [6]. Nghiên cứu của Ali Ghorbani và cộng sự (2020) trên bệnh nhân lọc máu ở Iran cho thây, dựa vào chỉ số SGA có $18,8 \%$ số bệnh nhân có suy dinh dưỡng mức độ nhẹ và trung bình và có $10,9 \%$ số bệnh nhân có mức độ suy dinh dưỡng nặng [3]. Nguyên nhân gây giảm BMI ở nhóm bềnh nhân này là do bệnh nhân ăn kiêng, giảm hấp thu của cơ quan tiêu hóa, cuộc lọc tiêu hao nhiêuu năng lượng và tình trạng bệnh nhân mắc các bệnh mạn tính khi lọc máu dài ngày dẫn đến giảm cân, teo cớ, giảm lớp mõ dưới da của bệnh nhân [2].

Albumin là một protein đơn giản hình cầu, tan trong nước, có chu kỳ tuần hoàn 15-20 ngày, tạo $70-80 \%$ áp suất keo và liên kết vận chuyển các chất có trọng lượng phân tử nhỏ như: bilirubin, hormon steroid, acid béo, và các thuốc có trong máu... Albumin được phân bố ở dịch ngoại bào và hơn $60 \%$ nằm trong khu vực ngoai mach, có $95 \%$ albumin do gan sản xuất, khi chức năng gan giảm, albumin giảm, nước không được giữ lại ở trong lòng mạch mà vào khoang gian bào gây ra hiện tượng phù (phù dinh dưỡng). Nó cũng là một chì số thường dùng nhất để đánh giá tình trạng dinh dưỡng [2].

Trong nghiên cứu của chúng tôi, $26,9 \%$ số bệnh nhân có nồng độ albumin huyết thanh $<35 \mathrm{~g} / \mathrm{l}$ và không có sự khác biệt có ý nghĩa thống kê giữa nam so với nữ (p > 0,05), tỷ lệ này trong nghiên cứu của Nguyễn Thị Vân Anh (2008) là $32,3 \%$, của Nguyễn Thị Thu Hà năm 2005 là $27 \%$. Nghiên cứu của Jin Woo Wi và cộng sự (2017) trên bệnh nhân lọc máu ở Hàn Quốc cho thây nồng độ albumin trung bình của bệnh nhân lọc máu là 39,5 $50,33 \mathrm{~g} / \mathrm{l}$ [3].

Sắt là một thành phần quan trọng trong tổng hợp hemoglobin (chất vận chuyển oxy cho các tế bào trong cơ thể) và myoglobin (chất dự trữ oxy cho cơ thể). Ngoài ra sắt còn tham gia vào thành phần một số enzyme- những chất xúc tác sinh học quan trọng trong cơ thể. Do đó thiếu sắt sẽ gẩy ra tình trạng thiếu máu thiếu sắt và ảnh hưởng đến hoạt động chuyển hoá của tế bào do thiếu hưt các men chứa sắt. Trong nghiên cứu của chúng tôi, nồng độ sắt huyết thanh dưới ngưỡng bình thường có 52 bệnh nhân chiếm
$50 \%$ và tỷ lệ bệnh nhân có thiếu máu là $93,3 \%$ trong đó có $14,4 \%$ bệnh nhân thiếu máu nặng, $31,7 \%$ bệnh nhân thiểu máu vừa và $47,2 \%$ bệnh nhân thiếu máu nhẹ. Nghiên cứu của Nguyễn Thị Thu Hà (2005) trên bệnh nhân bệnh thận mạn lọc máu thì tỷ lệ thiếu máu là $94,0 \%$. Nghiên cứu của Melissa E. Stauffer và cộng sự (2014) ở Mỹ cho thấy có $53,4 \%$ bệnh nhân bệnh thận mạn giai đoạn 5 có thiếu máu [5]. Một số yếu tô khác liên quan có thể giải thích tỷ lệ thiếu máu cao: Sản xuất thiếu Erythropoietin là nguyên nhân chính của thiếu máu trong bệnh thận mạn, đây là hormone có tác dụng kích thích sự biệt hoá hồng cầu - từ giai đoạn hồng cầu non đến hồng cầu trưởng thành. Thận là cơ quan chính sản xuất trên $90 \%$ erythropoietin trong cơ thể. Khi các cầu thận bị tổn thương (teo nhỏ, xơ hoá) thì lượng erythropoietin sẽ giảm sút gây thiếu máu. Nguyên nhân tiếp theo là giảm đời sống hồng cầu trong tình trạng nhiễm toan chuyển hoá, tủy xương bị ức chế do nhiễm độc mạn tính gây nên. Bên cạnh đó, quá trình lọc máu cũng làm mất máu, làm tăng khả năng tan vỡ hồng cầu, càng thúc đẩy mức độ thiếu máu ở những bệnh nhân bệnh thận mạn. Thiếu máu còn do tình trạng kém dinh dưỡng, kém hấp thu của đường tiêu hoá. Nên việc điều trị thiếu máu cho bệnh nhân bệnh thận mạn giai đoạn cuối là rất quan trọng, nhằm phòng những rối loạn về tim mạch và giảm tỷ lệ tử vong. Điều trị thiếu máu tốt giúp bệnh nhân đõ̃ mệt mỏi, làm tăng cảm giác ngon miệng, tăng hoạt động cơ thể và các chức năng sống khác.

Về mối liên quan giữa tình trạng suy dinh dưỡng với thời gian lọc máu, kết quả nghiên cứu của chúng tối cho thấy tỷ lệ suy dinh dưỡng có liên liên quan với thời gian lọc máu. Những bênh nhân có thời gian lọc máu < 1 năm có tỷ lệ suy dinh dưỡng thấp nhất theo các cách đánh giá và tăng dần theo thời gian lọc máu, nhóm bệnh nhân có thời gian lọc máu $>5$ năm có tỷ lệ suy dinh dưỡng cao nhất, sự khác biệt có ý nghĩa thống kê với $p<0,05$. Như vậy, thời gian lọc máu càng dài, mức độ suy dinh dưỡng càng nặng, điều này cho thấy các nhà lâm sàng cần chú ý hơn nữa chế độ dinh dưỡng cho những bệnh nhân bệnh thận mạn lọc máu chu kỳ.

\section{KẾT LUÂN}

- Tỷ lệ bệnh nhân thiếu cân theo BMI là $26,1 \%$; tỷ lệ bệnh nhân có albumin huyết thanh thấp $(<35,0 \mathrm{~g} / \mathrm{l})$ là $26,9 \%$; đánh giá nguy cơ tổng thể theo chỉ số SGA thì tỷ lệ nguy cơ thiểu dưỡng mức độ $\mathrm{B}$ là 40,4\%. 
- 14,4\% bệnh nhân thiếu máu nặng; 31,7\% bệnh nhân thiếu máu vừa và $47,2 \%$ bệnh nhân thiếu máu nhẹ.

- Có mối liên quan giữa tình trang suy dinh dưỡng (ở cả 3 tiêu chí đánh giá: BMI, Albumin huyết thanh và chỉ số SGA) với thời gian lọc máu $(p<0,05)$.

\section{TÀI LIÊU THAM KHẢO}

1. Hội Tiết niệu - Thận học Việt Nam (2013), "Chẩn đoán và đánh giá thiếu máu trong bệnh thân man, Hướng dẫn điều trị thiếu máu trong bệnh thận mạn".

2. Chung S., Koh E. S., Shin S. J., Park C. W. (2012), "Malnutrition in patients with chronic kidney disease," Open J. Intern. Med., vol. 02, no. 02, pp. 89-99.

3. Ghorbani A., Hayati F., Karandish M., Sabzali S. (2020), "The prevalence of malnutrition in hemodialysis patients," J. Ren. Inj. Prev., vol. 9, no. 2, pp. e15-e15.

4. Hisham M. T. (2019), "Assessment of Malnutrition in End Stage Renal Disease Patients on Hemodialysis," J. Clin. Trials, vol. 9, no. 4, pp. 367-372.

5. Stauffer M. E. , Fan T. (2014), "Prevalence of anemia in chronic kidney disease in the United States," PLoS One, vol. 9, no. 1, pp. 2-5.

6 Wi J.' W. , Kim N.-H. (2017), "Assessment of Malnutrition of Dialysis Patients and Comparison of Nutritional Parameters of CAPD and Hemodialysis Patients," Biomed. Sci. Lett., vol. 23, no. 3, pp. 185-193.

7. Xu Y. C. , Vincent J. I. (2020), "Clinical measurement properties of malnutrition assessment tools for use with patients in hospitals: A systematic review," Nutr. J., vol. 19, no. 1, pp. 1-12.

8. Zha Y., Qian Q. (201 7), "Protein Nutrition and Malnutrition in CKD and ESRD.," Nutrients, vol. 9, no. 3.

\section{THỰC TRANG SỬ DỤNG DỊCH VỤ CẤP CỨU Y TẾ CỦA NGƯ DẦN VEN BIỂN TẠI THÀNH PHỐ ĐÀ NẪNG}

\section{TÓM TẮT}

Mục tiêu: mô tả thực trạng sử dụng dịch vụ cấp cứu y tế của ngư dân ven biển thànhं phố Đà Nẵng. Đối tượng và phương pháp: Nghiên cứu mô tả cắt ngang trên 480 đối tượng là ngư dân đang trú tại thành phố Đà Nẵng. Kểt quả: Tỳ lệ sử dụng dịch vụ cấp cứu y tế là $54,6 \%$, lý do cấp cứu y tế chủ yếu là tai nạn thương tích chiếm $34,4 \%$ và nguyên nhân cấp cứu do bênh lý khác chiếm 20,2\%. Có $51,7 \%$ đối tượng nghiên cứu được hỏi không có trang bị đồ dùng sơ cấp cứu tại tàu, có $48,3 \%$ có trang bị các vật tư cớ bản để sơ cẩp cứu tại tàu như bông, bằng, cồn, gạc. Kết luận: Tỷ lệ sử dụng dịch vụ cấp cứu y tế của ngư dân ven biển còn cao, do đó cần tiến hành các biện pháp can thiệp đến dịch vụ cấp cứu y tế biển đảo để giải quyết vấn đề này kịp thời.

Tư khóa: Tai nạn thương tích, cấp cứu, ngư dân.

\section{SUMMARY}

SITUATION OF USE OF MEDICAL

EMERGENCY SERVICES OF COASTAL FISHERS IN DA NANG CITY

Objective: describe the current situation of using emergency medical services of coastal fishermen in Da Nang city. Subjects and methods: A cross-sectional

${ }^{1}$ Trường Đại học Kỹ thuật $Y$ - Dược Đà Nã̃ng Chịu trách nhiệm chính: Nguyễn Khắc Minh Email: minh@dhktyduocdn.edu.vn

Ngày nhận bài: 10.5.2021

Ngày phản biện khoa học: 28.6.2021

Ngày duyệt bài: 8.7.2021
Trần Đình Trung ${ }^{1}$, Hoàng Hữu Khôi ${ }^{1}$, Nguyễn Văn Song ${ }^{1}$, Nguyễn Khắc Minh ${ }^{1}$

descriptive study on 480 fisherfolk living in Da Nang city. Results: The rate of using emergency medical services is $54.6 \%$, the main reason for medical emergency is accidents and injuries accounted for $34.4 \%$ and emergency causes due to other diseases accounted for 20.2 . \%. There are $51.7 \%$ of the research subjects surveyed not equipped with first aid equipment at the ship, $48.3 \%$ are equipped with basic supplies for first aid on the ship such as cotton, bandages, alcohol, gauze. Conclusion: The rate of using emergency medical services by coastal fishermen is still high, so it is necessary to conduct interventions to medical emergency services in order to solve this problem in a timely manner.

Keys: Accident, injury, emergency, fisherman.

\section{I. ĐẶT VẤN ĐỀ}

Nghiên cứu này được thực hiện ở các phường thuộc ven biển của thành phố Đà Nẵng nhằm tìm hiểu những vấn đề về thực trạng sử dụng dịch vụ cấp cứu, xử trí tình huống cấp cứu, thói quen sử dụng các phương tiện trong vận chuyển cấp cứu của ngư dân....nhằm phát hiện một số tồn tại để góp phần bổ sung cho chính sách cấp cứu y tế nhân dân ngày càng công bằng và hiệu quả hơn. Chính vì vậy, chúng tôi tiến hành đề tài này nhằm mục tiêu: Mô tả thực trạng sử dụng dịch vụ cấp cứu y tế của ngư dân ven biền tại thành phố Đà Nẵng.

II. ĐỐI TƯợNG VÀ PHƯƠNG PHÁP NGHIÊN CỨU

2.1. Đối tượng nghiên cứu. Ngư dân là 